\title{
The Role of Social- Cognitive References in Academic Situations on Students' Research Self-Efficacy and Research Motivation: Testing a Causal Model
}

\author{
Monireh Salehi', Hossein Kareshki ${ }^{2, *}$, Mohammad Reza Ahanchian ${ }^{2}$ \\ ${ }^{1}$ Shahid Beheshti University, Tehran, Iran, \\ ${ }^{2}$ Ferdowsi University of Mashhad, Mashhad, Iran \\ *Corresponding author: kareshki@um.ac.ir
}

Received December 19, 2012; Revised April 20, 2013; Accepted April 26, 2013

\begin{abstract}
The purpose of the present study was to investigate the relation between factors that effect on research products, research self-efficacy and research motivation in students applying a causal model. The method used this descriptive study was structural equation modeling (SEM) which is an advanced correlative method. A sample of 126 PHD students was selected from two Universities in North western of Iran. Participants responded to research self-efficacy, research motivation and research factor scales. Pearson correlation coefficients showed that most of the research self-efficacy factors, research motivation factors (internal motivation, external motivation and being motiveless) and components of research factors (previous experiences, others encouragement, substitute experiences, anxiety and attitude) are significantly correlated $(\mathrm{p}<0 / 05)$. SEM results revealed the mediating role of research selfefficacy in relation between research factors and research motivation (NNFI=0/90, RSMEA= 0/06); and most of the path coefficients of the suggested model were significant $(\mathrm{p}<0 / 05)$. Based on this result, we can calculate that environmental factors in university have effects on student's performance in research.
\end{abstract}

Keywords: self-efficacy, research, motivation, PhD student, factors

\section{Introduction}

One of concerns of professors, academic authorities and policymakers, is to identify and explore the factors which affect students' research motivation [1]. This is also one of the main interests for theorists and researchers of psychology and education, particularly in the field of motivation and learning $[2,3,4]$. A theory which focuses on the effect of self along with environment and behavior on the learning process is Bandura's Social Cognitive Theory [2]. It was based on this theory that theorisians and researchers offered the Social-Cognitive model of selfregulation [1]. According to Zimmerman and Bruner, the highest level of learning is being self-regulated which allows learners to adjust their learning strategies to contextual and personal changes. In this level, learners may be able to start using strategies, adapt themselves with contextual and circumstantial characteristics and be motivated by self-efficacy perceptions of potential situations. So, they consider self-efficacy beliefs as an important motivational source in this level [4]. Selfefficacy is the person's judgment about his/her abilities to organize and perform some actions to achieve desirable goals and functions [5-10], and one of these functions may be researching. Lev, Kolassa \& Bakken [11] and Unrau \& Beck [12] assert that one of the main effective factors on doing research by students is research self-efficacy which is the confidence on their abilities to conduct research.
Forester, Kahn and Hesson-McInnis [13] consider research self-efficacy to be the people's confidence on themselves to carry out research successfully. Those people with low research self-efficacy may refuse to do researches; but those who believe in their abilities are likely to undertake research. The question is that what is the best method to promote self-efficacy? Which factors are involved in its emergence? Is self-efficacy a basic skill which can be improved? Or is it promoted through changes in the value structure of the person? According to Bandura [2], people gather real information to evaluate their self-efficacy from their real performances, substitute experiences (observational), different methods of persuasion and physiological symptoms (Arshadi, 14, 15, 9,4). Moreover, according to Bandura's social cognitive theory [2], there are four ways to promote self-efficacy: The first method is verbal encouragement; for instance "you can do this research". Or a professor may say to a student that there is no doubt about his/her abilities. It means that teacher's expectations influence student perception of his/her abilities. Encouragement is one of the oldest ways to perform works by means of others. This method is a simple and available one. Professors, teachers and parents should consider that learners are capable of self-efficacy improvement. Therefore, their expectations affect the self-efficacy and the performance of learners [16]. Most of the young people assert that there are significant individuals in their lives that cause the improvement of their motivation and efficacy [17]. In this regard, Lev et al. (2010) conducted a research on the 
relation between students' research self-efficacy and the professors' perception of students' efficiency. The findings revealed a significant positive correlation between students' research self-efficacy and professors' judgment about their efficiency. This relation is also supported by Bandura's point of view which implies that a wrong judgment about students' efficiency may lead to avoiding educational opportunities. A teacher, who has not a proper evaluation on students' efficiency, may not be able to give beneficial and informative feedbacks. Three other factors should be noted along with verbal encouragement: physiological arousal, substitute experiences and previous experiences. Although professors do not directly transfer students' self-efficacy to them, these four sources are always available to the students and they can assure of their research ability by means of them. For instance, a student who suffers of high heart rate, dry mouth and anxiety before the defense session has a low self-efficacy (physiological arousal). In this circumstance, he/she consider others as the judge of his/her potential competence. Unrau \& Grinnell [18] asserted that students are more concerned and anxious about MA or PHD thesis than they actually assume. They conducted a study on social work students and found that most of the research methodology professors noticed students' anxiety on doing their theses. By contrast, Lazar [19] indicated that professors underestimated students' anxiety. It should be noted that professors and their various research practices influence the learning environment. Learning environment and context consists of professors' knowledge and their method and manner which affect students' feeling about research [20]. A student who has observed the failure of other people may feel incompetent and vice versa; a phenomenon which is named substitute experiences by Bandura [15]. Substitute experience is determined as observing other people who are considered as our model and have the same tasks as we do. People's successful and failed experiences in research can be considered as previous experiences. It should be noted that the transferred knowledge to students has a lower effect on self-efficacy compare to the information that individual obtain from the performances of themselves and others [21]. Professors' manner and behavior in addition to classmates' performances may influence research self-efficacy. Observation of others success and failure is particularly significant when individual has less experience regarding the task [22]; and finally it should be noted that individual's previous experiences are the most crucial factors in developing and maintaining the perceived ability [22,23,24]. It means that person assures about the future, observing his/her previous success; in contrast he/she would be hopeless if he/she failed in the past. Successes improve efficacy and failures make it weak; but according to Bandura [2] if efficacy beliefs are strong, failure may not affect them [21]. Hemmings and Kay [25] conducted a study on the effect of real experiences on research self-efficacy in a sample of university professors considering their research skills and the fact that they have published papers or not. Findings showed a significant difference between those professors with research products and those without them. In general, people consider all effective factors on their efficiency, evaluating their research self-efficacy. Factors such as perception and affection about their abilities, the difficulty of the task, required effort, the amount help that is needed of others, the quantity and type of successes and failures, similar models that they have observed and acceptable incentives [21].

Rosenblatt and Kirk [26] have confirmed the importance of actual knowledge and its effect on students' attitude toward research. They found that developing the literature of the research support students' attitude toward research and have a positive effect on their knowledge of research concepts and methods; in addition, students' knowledge and attitude to research are related to their progress in conducting more research. Olsen [27] found that students' attitute toward research promots along with their improvment on statistics and research methodology. This issue is patrticularly observed in comprison between under graduate and graduates students [28]. Therfore, it seems that students' knowledge of essential skills for reseach and the way that these skills would be obtained is positivly related to their self-efficacy. Moreover, students' success in courses such as research methodology, statistics, sampling, and computer science which are related to research correlates with their research self-efficacy. In this regard, Rosenblatt \& Kirk [26] found that there is a significant relation between the attitude toward courses which are related to research (such as research methodology and statistics) and research self-efficacy.

Whereas, research products are importan in Universities situations, stuudding factors that effect on theirs is a necessity. For this poupose, Motivation to research, factors and beliefs that related to its such as self-efficacy, are essential. Various research have been done in this domain or more general domains. In this regard, Yailagh, Loyd, and Walsh[29] investigated the relation between students' different attributions, math self-efficacy beliefs, and gender and math achievement. Findings of this study revealed that attributions (a motivation belief) predicted math self-efficacy. In addition, students' goal setting (a motivation belief) can also be predicted by self-efficacy and those who attributed their success to internal causes, showed higher self-efficacy. Pajares[30] considered selfefficacy as the most significant theme for motivational studies. Bailey [31] asserted that self-efficacy is effective in focusing and controlling the energy to achieve goals. His study, educational motivation and teaching and research self-efficacy, has been conducted on a sample of university professors in for levels of instructor, assistant professor, associate professor and professor. This study revealed a relatively high and positive relation between research self-efficacy and research motivation.

Considering the crucial role of research factors (socialcognitive factors) in research motivation and self-efficacy and also given the role of self-efficacy on motivation which is supported theoretically, it can be concluded that self-efficacy may moderate the relation between effective factors on research and research motivation (Figure 1). This model tests the relations that have not studied in research domain yet. Research problem is that, can this model -that based on social-cognitive theory- fit to $\mathrm{PhD}$ students and other researchers? Can this model apply to research situations whereas it developed to more general domains? Can psychological Occasions governing in general situations extended to research situations? Base theory say that it is possible but we need to evidence to support it. 


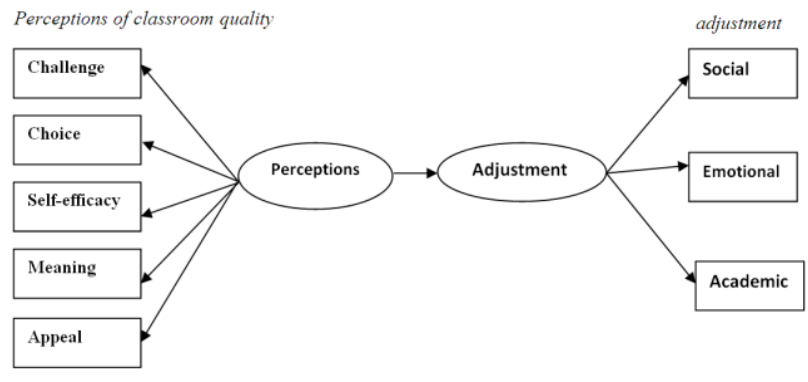

Figure 1. Proposed model for the relations between factors, research self-efficacy and motivation

Therefore, the purpose of the present study is to investigate the role of research factors on research motivation with mediation of research self-efficacy using a structural casual model. In the suggested model, the factor structure of research self-efficacy consists of 7 components: analytical and statistical self-efficacy, selfefficacy in conceptualization, self-efficacy in method, self-efficacy in qualitative research, self-efficacy in reporting, self-efficacy in skills and self-efficacy in ethics. To identify these factors the ideas of Newman [32], Forester, Kahn and Hesson-McInnis [13], Holden, Barker, Meenachan, and Rosenberg [33], Phillips \& Russell [34] and Borg \& Gall [35] and opinions of research methodologists have been used. Moreover, the 3 factor structure of research motivation which is based on the self-determination theory [36] and includes internal and external motivation and being motiveless has been tested.

\section{Method}

To explore the relation between variables in this descriptive study the method of structural equation which is a subset of correlation methods had been used. Data were gathered by means of questionnaires.

\subsection{Participants}

To conduct the study two target populations were selected. The first and the main research target population include all $\mathrm{PhD}$ students of the faculties of education, literature, economics, agriculture, paramedics, Dentistry, Pharmacy, Health and Medicine. Using available sampling method, $126 \mathrm{PhD}$ students were selected from two universities. The second population of the study, with the aim if developing research tools, includes all the higher education students (MA \& PhD) of Ferdowsi University and Medicine Science University of Mashhad. The required sample size for this purpose was estimated to be 280.

\subsection{Materials}

To gather the data three scales of research self efficacy, research motivation and research factors were used which were developed by authors. The validity and reliability of these scales were confirmed in this study.

Research self-efficacy scale: This 55-item scale consists of 7 subscales: analytical and statistical self-efficacy, selfefficacy in conceptualization, self-efficacy in method, self-efficacy in qualitative research, self-efficacy in reporting, self-efficacy in skills and self-efficacy in ethics.
Items are rated on a 7-point scale. In the present sample, reliability estimated by alpha coefficient was $0.92,0.91$, $0.90,0.92,0.88,0.76$, and 0.83 for each of the subscales that mentioned above, respectively and 0.97 for the overall scale. The validity of this scale was confirmed using confirmatory factor analysis (CFA). Results are: RSMEA=0/093, $\chi 2=3794.69, \mathrm{df}=1409$.

Research motivation scale: This scale consists of 28 items (based on self-determination theory, 37, and 38) which are rated on Likert scale. Internal consistency (Alfa) of the subscales (internal motivation, external motivation and being motiveless) was $0.93,0.88$ and 0.76 and the overall internal consistency of the scale was 0.89 . The construct validity of this scale was confirmed using SPSS and LISREL software by CFA (RSMEA=0/093, $\chi 2=3794.69, \mathrm{df}=1409$ ).

Research factors questionnaire: This 14-item scale which gathers some information on students, research products such as papers, seminars etc, consists of 5 subscales of previous experiences, professors, encouragement, anxiety, substitute experiences and attitude toward the course. The reliability of 7-item Professors' expectations and encouragements questionnaire was 0.89 using KR20. The questionnaires of anxiety, stress and substitute experience consist of 6 yes/no items. The reliability of theses tow scales were 0.78 and 0.90 using KR20. The 30-item Students' attitude toward research questionnaires showed the Cronbach's alpha of 0.81 for research methodology, 0.80 for computer and 0.82 for statistics.

\subsection{Data Treatment and Confirmation of Suitability for SEM}

The data of the study include the scores of participants on all of the research variables. Each participant had an overall score for research self-efficacy, 7 scores for research self-efficacy subscales, 3 scores for internal and external motivation and being motiveless; 5 scores for previous experiences, substitute experiences, others encouragement, attitude and anxiety. To analyze and report the data some descriptive indexes such as mean and standard deviation were used. Structural equation modeling (SEM) was applied to test the model and Pearson correlation and lambda $(\lambda)$ coefficients in SEM were used to test other hypotheses. In addition to examining the zero-order correlation coefficients, the relations represented in the proposed model were also examined using structural equation modeling (Figure 1). Structural equation modeling is a statistical method for studying causal non experimental relations in situations that several variables including mediating variables are involved. To refine the data, the missing data were changed to the means, and outliers to the nearest data. To make sure that there are no similarity between variables of the research, multicolinearity indexes [39] and other related characteristics of the data were obtained, and no co-linearity was found (Table 1). Regression for predicting research self-efficacy and motivation show that variance inflation factors (VIFs) are lower than 10 . Therefore, variables are different from each other and no co-linearity is observed. Therefore, the results of regression or structural equation modeling analysis are trustable [39]. However, having refined the data, to test the proposed model, LISREL 8.53 was used. 


\section{Result}

Research findings are presented here in two formats: descriptive and correlation analysis (testing of proposed model). Table 1 represents the means, standard deviations and Pearson correlations for students' research motivation (amotivation, external motivation and external motivation,), students' research self-efficacy components and research factors (previous experiences, professors 'encouragement, anxiety, substitute experiences and attitude toward the course).

Structural Equation Model. As Figure 2 shows, the indexes of proposed model were acceptable and the obtained $\chi^{2}$ was not statistically significant. (RSMEA= 0/067, $\left.\chi^{2}=112 / 11, \mathrm{df}=74, \mathrm{NNFI}=0 / 90, \chi^{2 /} \mathrm{df}=1 / 51\right)$. Standard references suggest that If NFI are above .90, $\chi^{2} / \mathrm{df}<3$, RSMEA $<.05$, fit indexes of the model would be acceptable (Kline, 1994). See Figure 2 for path coefficients and other results.

Table1. Statistic and correlation coefficients between components of research self efficacy, research motivation and research factors

\begin{tabular}{|c|c|c|c|c|c|c|c|c|c|c|c|c|c|c|c|c|}
\hline Variables & M & SD & 1 & 2 & 3 & 4 & 5 & 6 & 7 & 8 & 9 & 10 & 11 & 12 & 13 & 14 \\
\hline 1-past experiences & 100.33 & 92.82 & - & & & & & & & & & & & & & \\
\hline 2- Attitude to courses & 54.35 & 8.67 & .16 & - & & & & & & & & & & & & \\
\hline 3- other persuasion & 4.49 & 2.33 & $.43^{* *}$ & .09 & - & & & & & & & & & & & \\
\hline 4- vicarious experiences & 3 & 2.43 & -.02 & .09 & .08 & - & & & & & & & & & & \\
\hline 5-Anxiety & 2.11 & 1.77 & -.04 & -.08 & .03 & .16 & - & & & & & & & & & \\
\hline 6-statistic analysis & 42.34 & 9.63 & $.36^{* *}$ & $.40^{* *}$ & $.31^{* *}$ & .07 & -.11 & - & & & & & & & & \\
\hline 7- conceptualizing & 44.04 & 7.04 & $.39^{* *}$ & $.20^{*}$ & $.36^{* *}$ & .07 & -.16 & $.53^{* *}$ & - & & & & & & & \\
\hline 8-adminsrating & 35.83 & 6.45 & $.45^{* *}$ & $.23^{* *}$ & $.35^{* *}$ & -.02 & -.12 & $.65^{* *}$ & $.69^{* *}$ & - & & & & & & \\
\hline 9-Quality & 13.31 & 4.72 & $.20^{*}$ & .15 & $.18^{*}$ & -.02 & -.1 & $.39^{* *}$ & $.40^{* *}$ & $.46^{* *}$ & - & & & & & \\
\hline 10- Reporting & 21.52 & 4.33 & $.37^{* *}$ & .14 & $.34^{* *}$ & .09 & .02 & $.60^{* *}$ & $.74^{* *}$ & $.61^{* *}$ & $.44^{* *}$ & - & & & & \\
\hline 11- Mastery & 18.5 & 3.34 & $.20^{*}$ & $.26^{* *}$ & .14 & .03 & -.08 & $.39^{* *}$ & $.62^{* *}$ & $.50^{* *}$ & $.35^{* *}$ & $.55^{* *}$ & - & & & \\
\hline 12- ethic & 11.39 & 2.21 & $.18^{*}$ & $.21^{*}$ & $.27^{* *}$ & .04 & .09 & $.46^{* *}$ & $.52^{* *}$ & $.38^{* *}$ & $.22^{*}$ & $.60^{* *}$ & $.45^{* *}$ & - & & \\
\hline 13-Amotivation & 7.35 & 3.02 & $.39^{* *}$ & $.26^{* *}$ & $.31^{* *}$ & $.18^{*}$ & -.01 & $.43^{* *}$ & $.47^{* *}$ & $.52^{* *}$ & $.25^{* *}$ & $.49^{* *}$ & $.39^{* *}$ & $.35^{* *}$ & - & \\
\hline 14-external motivation & 22.81 & 6.08 & .13 & .11 & .09 & $.18^{*}$ & .04 & 0.16 & $.25^{* *}$ & $.23^{* *}$ & .13 & $.28^{* *}$ & $.19^{*}$ & $.18^{*}$ & $.37^{* *}$ & - \\
\hline 15- internal motivation & 42.2 & 9.17 & $-.24^{* *}$ & -.16 & $-.25^{* *}$ & -.08 & .08 & $-.31^{* *}$ & $-.34^{* *}$ & $-.31^{* *}$ & .03 & $-.38^{* *}$ & $-.22^{*}$ & $-.34^{* *}$ & $-.53^{* *}$ & -.16 \\
\hline
\end{tabular}

The fit indexes showed that obtained data fitted with the proposed model. It means that research factors were related to research motivation and predicted it through mediating research self-efficacy. In other words, relations among research factors with research motivation are affected by research self-efficacy.

Structural equation modeling indexes also contain standard regression coefficients or structured relations with sizes from 0.00 to 1.00 ( $\beta$ or $\gamma$ in Figure 2$)$. $\beta$ is standard regression coefficient (path coefficient) from exogenous variables to endogenous variables, and $\gamma$ is standard regression coefficient from endogenous variables to other endogenous variables. The $\gamma$ coefficients from previous experiences, professors 'encouragement, and attitude toward the course to research self-efficacy are significance statistically, but from anxiety and vicarious experiences to research self-efficacy not significance statistically. The $\beta$ coefficients from previous experiences, professors' encouragement, and attitude toward the course to research motivation are not significance statistically, but from vicarious experiences to research motivation is significance statistically.

Multiple correlations squared $\left(R^{2}\right)$ indicate that the proposed model explains $31 \%$ of the variance in research motivation by means of research factors and self-efficacy, and mediating research self-efficacy. The $\beta$ coefficient from research self-efficacy to research motivation is significance statistically $(\beta=0 / 53, \mathrm{t}=4 / 79, \mathrm{p}<0 / 05)$.

\section{Discussion}

The main purpose of this study was to investigate the effect of research factors including previous experiences, encouragement, anxiety, substitute experiences and attitude on research self-efficacy and research motivation of PHD students. According to findings, research selfefficacy which consists of analytical and statistical selfefficacy, self-efficacy in conceptualization, self-efficacy in method, self-efficacy in qualitative research, selfefficacy in reporting, self-efficacy in skills and ethics had a meditative role. Moreover, research motivation consists of internal motivation, external motivation and being motiveless. The relations between these variables were tested using structural equation modeling (SEM). The results revealed that our suggested model which is based on strong theoretical and empirical bases has a proper fitness with the data. Overall indices such as path coefficients and t test confirmed this fitness. Therefore, there is an explanatory relation between previous experiences, encouragement, anxiety, substitute experiences and attitude and also between research selfefficacy and research motivation; According to this explanatory relation, previous experiences, encouragement, anxiety, substitute experiences and attitude affect research motivation factors with the mediation of research selfefficacy. In other words, research self-efficacy revealed its meditative role very well. It means that the quality of the relation between previous experiences, others encouragement, anxiety, substitute experiences, attitude and research motivation is dependents on individual's research self-efficacy. On the other hand, research motivation was not directly predicted by previous experiences, encouragement, anxiety, substitute experiences and attitude. Furthermore, proper and significant relations between research self-efficacy factors and overall research self-efficacy and also between research motivation and its components were revealed. 


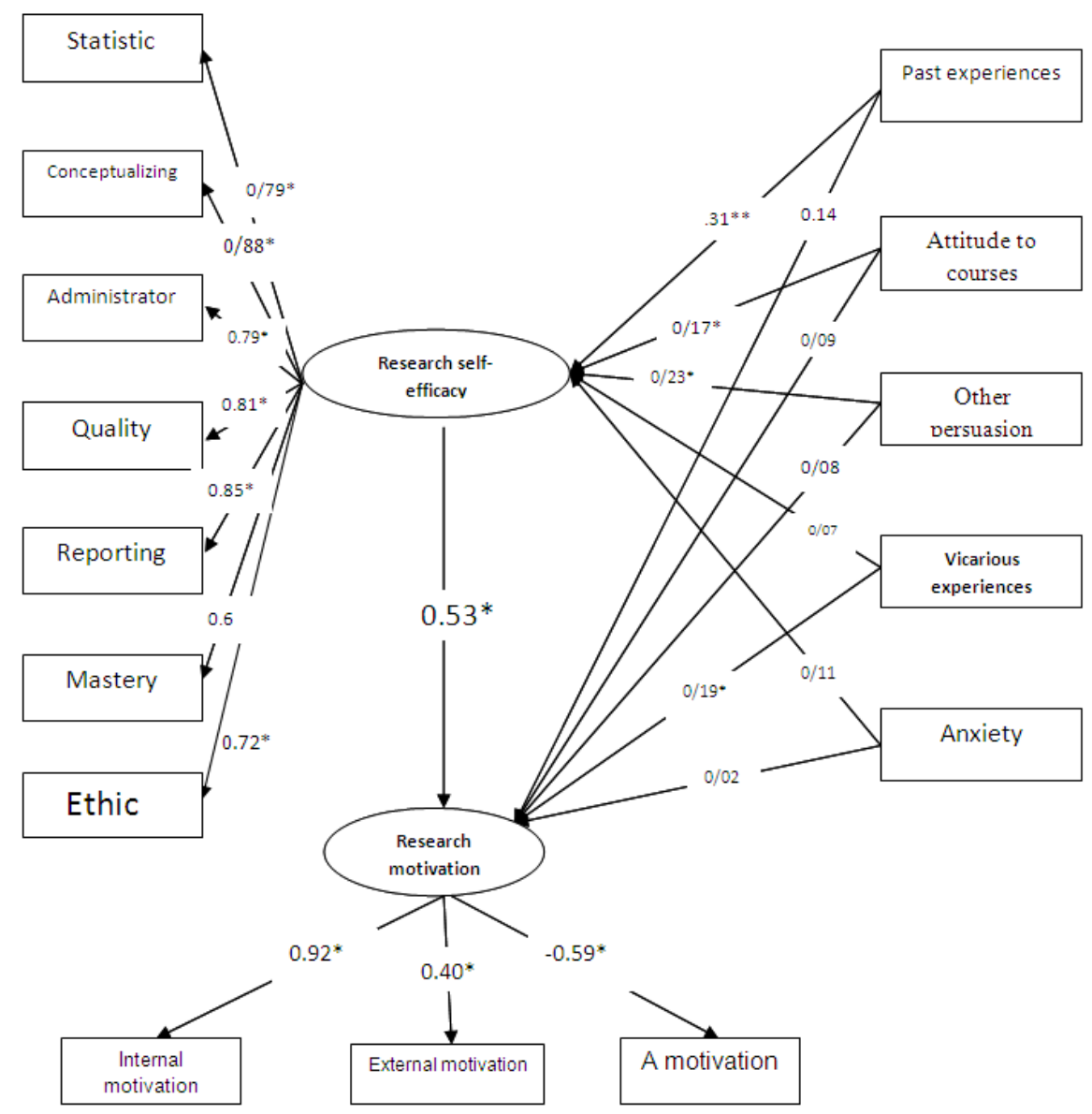

(s) indicates the closest observed variable to the latent variable in the structural equation model. Model fit parameters: RSMEA $=0 / 067, \chi^{2}=112 / 11$, $\mathrm{df}=74, \mathrm{NNFI}=0 / 90, \chi^{2} / \mathrm{df}=1 / 51 \mathrm{R}^{2}=0.31$. The numbers before parenthesis are path coefficients and the numbers inside parenthesis are $\mathrm{t}$ values showing the significance of path coefficients.

Figure 2. Tested model of the structural relations between research motivation, students' research self-efficacy components and research factors

These finding are consistent not only with the self determination [37] and Bandura's social cognitive (Pintrich \& Schunk, 4) theories, but also with the results of other studies. Bailey [31] conducted a research on the effect of teaching and research self-efficacy on the teaching and research motivation. This study on a sample of university professors in for levels of instructor, assistant professor, associate professor and professor revealed that there is a strong relation between teaching and research self-efficacy and the teaching and research motivation. This result is similar to ours; but the difference is that Bailey solely compared 4 groups and investigated the relation between research self-efficacy and motivations. The present study conducted to exploring the effective factors on self-efficacy and their direct and indirect influences on motivation. Another study with similar results to our research was conveyed by Arshadi [14]. The finding of this study on the role of self-efficacy on occupational motivation showed that self-efficacy influenced the occupational motivation. Moreover, Gao, Zan et al. [9] in a study on exploring students' motivation perception in sport, found that students are motivated to perform sport actions when they believe that they are able to do that. In another study on mountaineering and climbing Gomez and Hill [40] found that doubting one's ability to climb had a destructive effect on mountaineering. Moreover, Velez [15] in a thesis about effects of selfefficacy on educational motivation and achievement showed that students' performance could be maximized when students had a high motivation and self-efficacy regarding to their tasks. Switzer, Nagy and Mullins [41] also found a significant positive relation between selfefficacy and pre-education motivation. Pajares[16] believes that learners' self-confidence about their school learning and performance affects their effort to learn new subjects; and those learners who have higher self-efficacy, expand their efforts on learning new things and insist on difficult tasks. Therefore, the findings of the present study and relating studies indicate that people's beliefs about their ability of performing the task are related to their motivation toward that specific task. Indeed, those learners with high self-efficacy feel confident in achieving their goals. They try to identify their abilities, beliefs, strategies and also their mistakes to succeed. In contrast, a person with low self-efficacy on doing a task probably does not participate in that action. Individuals with high self-efficacy show more hard work and perseverance in the face of troubles comparing to those who doubt their competence. Research is one of the major tasks for PHD student. Feeling confidence in doing research and research self-efficacy may be an effective factor on students' participation in research. Shirbeigy and Salehi [42] found a significant positive relation between students' research self-efficacy and their attitude toward research. The finding of the present study also confirmed that research self-efficacy effected research motivation and it played a significant moderation in the relations of factors like students' research experiences, substitute experiences, 
others encouragement and anxiety. Hemmings and Kay [25] in a study regarding the effects of previous research experiences on research self-efficacy of professors, found a significant difference of self-efficacy between those professors with research outcomes and those without research experiences. This result is consistent with the findings of the present study which revealed a significant positive relation between research experiences and research self-efficacy of PHD students. Unrau and Grinnel's results [18], also indicated that real experience of research affected research self-efficacy.

According to Bandura, another effective factor on selfefficacy is substitute experience. The findings are not consistent with his point of view in this regard. In fact, although substitute experiences did not correlate with research self-efficacy, it was related to research motivation and this was the only factor which affected motivation through a direct path. Findings also confirmed a significant positive relation between others encouragement and research self-efficacy which is consistent with the result of Ley et al. [43]. They asserted that students' self-efficacy and professors' judgments about their efficiency correlated positively. Bandura [3] supported this relation and asserted that wrong judgment about students' efficiency may lead to loosing educational opportunities. Other effective factors on research selfefficacy are stress and anxiety which are related negatively to it according to the findings of the present study. This result supports Bandura's assumption about the effects of physiological states on research self-efficacy. The attitude toward the courses which are related to research is another effective element on research selfefficacy. Findings revealed a significant positive relation between research self-efficacy and students' attitude toward these courses. This result is consistent with Rosenblatt and Kirk's [26] findings which showed that developing the literature of the research support students' attitude toward research and has a positive effect on their knowledge of research concepts and methods.

Therefore, the issue which was explored in the present study was the casual relation of previous experiences, other people encouragement, substitute experiences and anxiety with research motivation with the moderation of research self-efficacy. Findings indicated that research self-efficacy influences research motivation and it played a significant moderation in the relations of factors like students' research experiences, substitute experiences, others encouragement and anxiety with research motivation. To explain these results, it should be noted that according to Bandura there is a three-way interaction between environment, behavior and learner's mind. It was revealed in this study that students' feeling about their abilities to research plays a crucial role in motivational outcomes of external factors. Thus, to enhance the motivation in doing research, students' feeling and beliefs about their abilities to conduct research should be considered in addition to previous experiences, other people encouragement, substitute experiences and anxiety. Those students with high self-efficacy about their abilities on doing research can control and manage the factors of their specific circumstances. In fact, both individual factors such as anxiety and external factors like professors' encouragement influence self-efficacy. Since people are different regarding to psychological issues and given the fact that external factors are not the same for all the people, it is hardly possible to find individuals with similar conditions to conduct research to which the same instruction of doing research can be given. The factors that have importance role in conducting successful research are individuals 'beliefs about their abilities. These are the beliefs that lead people to an optimize usage of available resources and motivate them to identify their weaknesses and strengths. As a result, individuals may correct their weaknesses or change the surrounding environment if it is possible; and if it is not they can identify the consequences and control their effect on their own beliefs and feeling.

Findings of the present study along with its theoretical bases encourage professors and educational designers to prepare teaching program in a way that educational environment lead to enhancement of students' research self-efficacy. Those students who are involved in real researches are able to prompt their experiences and consequently their research self-efficacy and motivation will be improved. According to findings, others encouragement is one of the major factors which affect research self-efficacy and motivation. Professors' encouragement and expressing their expectations of students lead to enhancement of students' self-efficacy and increase their motivation to conduct the research. In this case, students pass the difficulties in the way of doing research with more patience and put their maximum effort on achieving goals. Another effective factor on selfefficacy was students' attitude to related courses to research. According to the mentioned studies, improvement of learning and enhancement of students' knowledge in related areas to research such as statistics and research methodology is a crucial factor which leads to positive attitude. Therefore, professors should consider that enhancement of students' knowledge in related areas to research lead to improvement of attitude and consequently promotion of research self-efficacy and motivation. Another major factor for promoting research self-efficacy and motivation is decreasing students' stress and anxiety. Various studies suggest that most of the students deal with stress and anxiety working on their thesis and professors often underestimate their anxiety. Educational planners and curriculum designers should identify those factors which cause students' stress and anxiety and their solution. In addition, one of the factors which may be influential in decreasing students' anxiety is the method for selecting and defending research subjects which is used in each department. The more these methods are clear the fewer students endure stress.

The theoretical background and our findings provide a proper context to criticize higher education system regarding to the effect of educational environment on research self-efficacy and motivation and also the relation between students and professors which affects the anxiety, development of motivational research context and providing students and professors with proper research experiences. Most of the professors and educational authorities are not aware of the importance of their beliefs and behaviors on students' research self-efficacy and motivation and may unintentionally cause students' apathy. Therefore, it is essential to Plan and implement education with the aim of enhancing self-efficacy, developing useful motivational beliefs and creating environmental perceptions which encourage research. In 
addition to education, conveying related action researches and case studies is beneficial in achieving desired goals.

\section{References}

[1] Kareshki, H. The role of motivational belief and environmental perceptions on self-regulating learning in 3th grade of guidance school. PhD thesis in Educational psychology branch, Tehran University, Iran, 2008.

[2] Bandura, A. Social foundations of thought and action: A social cognitive theory. Englewood Cliffs, NJ: Prentice-Hall, 1986.

[3] Bandura, A. Self-Efficacy: The Exercise of Control. New York: Freeman, 1997.

[4] Pintrich, P. \& Schunk, D. Motivation in Education: Theory, Research \& Applications, Ch. 3. Englewood Cliffs, NJ: PrenticeHall, 2002.

[5] Sawtelle, V., Brewe, E., \& Kramer, L. H. Sequential logistic regression: A method to reveal subtlety in selfefficacy. In M. S. Plakhotnik, S. M. Nielsen, \& D. M. Pane (Eds.), Proceedings of the Tenth Annual College of Education \& GSN Research Conference (pp. 216-225). Miami: Florida International University, 2011.

[6] Moorefield-Lang, Heather M. Arts Voices: Middle School Students and the Relationships of the Arts to their Motivation and Self-Efficacy. The Qualitative Report, 15 (1), 1-17, 2010.

[7] Nelson, K. Differences in graduate and undergraduate performance in a core research course', Journal of Education for Social Work, 19, 77-84, 1983.

[8] Salami, Samuel O. Psychopathology and Academic Performance among Nigerian High School Adolescents: The Moderator Effects of Study Behaviour, Self-Efficacy and Motivation. Kamla-Raj, Journal of Social Science, 16(2): 155-162, 2008.

[9] Gao, Z; Lee, AM. and Harrison, JL. Understanding Students' Motivation in Sport and Physical Education: From the Expectancy-Value Model and Self-Efficacy Theory Perspectives. National Association for Kinesiology and Physical Education in Higher Education, Quest, 2008, 60, 236-254, 2008.

[10] Bin Hj Abd Wahab, M. Study on the Impact of Motivation, SelfEfficacy and Learning Strategies of Faculty of Education Undergraduates Studying ICT Courses. The Journal of Behavioral Science, 2(1): 151. 2007.

[11] Lev, EL., Kolassa, J. \& Bakken, L. Faculty mentors' and students' perceptions of students' research self-efficacy. Nurse Education Today. 30, 169-174, 2010.

[12] Unrau, Y. A. \& Beck, A. R. 'Increasing research self-efficacy among students in professional academic programs', Innovative Higher Education, 28(3), 187-294, 2004.

[13] Forester, M., Kahn, JH \& Hesson-McInnis, MS. Factor Structures of Three Measures of Research Self-Efficacy. Journal of Career Assessment, 12 (1), 3-16, 2004.

[14] Arshadi, N. Motivational Traits and Work Motivation: Mediating Role of Self-Efficacy. Journal of Education \& Psychology, 3(2), 67-80, 2009.

[15] Velez, Jonathan J. In structure communication behaviors and classroom Climate: exploring relationships with student selfefficacy and task value motivation. Dissertation Presented in Partial Fulfillment of the Requirements for the Degree Doctor of Philosophy in the Graduate School of The Ohio State University, 24(6), 639-651, 2008.

[16] Pajares, F. Self-Efficacy Beliefs of Adolescents. Copyright, by Information Age Publishing All rights of reproduction in any form reserved I, 2005.

[17] Astray-Caneda, V., Busbee, M., \& Fanning, M. Social learning theory and prison work release programs. In M. S. Plakhotnik, S. M. Nielsen, \& D. M. Pane (Eds.), Proceedings of the Tenth Annual College of Education \& GSN Research Conference. Miami: Florida International University, pp. 2-8, 2010.

[18] Unrau, YA. \& Grinnell, RM. The Impact of Social Work Research Courses on Research Self-Efficacy for Social Work Students. Social Work Education, 24 (6), 639-651, 2005.

[19] Lazar, A. Faculty, practitioner, and student attitudes toward research. Journal of Social Work Education, 27, 3440, 1991.

[20] Kahn, JH. \& Scott, NA. 'Predictors of research productivity among counseling psychology doctoral students', Counseling Psychologist, 25, 38-67, 1997.
[21] Shank, Dale H. (1991). Self-efficacy and academic motivation. Educational Psychologist, 26, 207-231.

[22] Sawtelle, V., Brewe, E., \& Kramer, L. H. Sequential logistic regression: A method to reveal subtlety in selfefficacy. In M. S. Plakhotnik, S. M. Nielsen, \& D. M. Pane (Eds.), Proceedings of the Tenth Annual College of Education \& GSN Research Conference (pp. 216-225). Miami: Florida International University, 2011.

[23] McFarland, Tracy. Factors influencing self-efficacy and motivation in the middle School mathematics classroom. A Project Submitted to the Faculty of The Evergreen State College In Partial Fulfillment of the Requirements for the degree Master in Teaching, 2010.

[24] Lewis, M. L. Self-Efficacy Manipulations in Protection Motivation Research: A Meta-Analysis. Doctorian dissertation, Department of Telecommunication, Information Studies, and Media Michigan State University.

[25] Hemmings, B. and Kay, R. Lecturer self-efficacy, research skills, and publication output. Australia, Charles Sturt University, 2008.

[26] Rosenblatt, A. \& Kirk, SA. Cumulative effect of research courses on knowledge and attitudes of social work students', Journal of Education for Social Work, 17, 26-34, 1981.

[27] Olsen, L. Integrating a practice orientation into the research curriculum: the effect on knowledge and attitudes. Journal of Social Work Education, 26, 155-161, 1990.

[28] Nilsen, Hallgeir. Influence on Student Academic Behaviour through Motivation, Self-Efficacy and Value-Expectation: An Action Research Project to Improve Learning. Issues in Informing Science and Information Technology, 6, 445-556, 2009.

[29] Yailagh, M. S., Lloyd, J. and Walsh, J. The Causal Relationships between Attribution Styles, Mathematics Self-Efficacy Beliefs, Gender Differences, Goal Setting, and Math Achievement of School Children. Journal of Education \& Psychology, 3(2), 95114, 2009.

[30] Pajares, F. Self-efficacy beliefs, motivation, and achievement in writing: A review of the literature. Reading \& Writing Quarterly, 19(2), 139-158, 2003.

[31] Bailey, Jeffrey G. 'Academics' Motivation and Self-efficacy for Teaching and Research', Higher Education Research \& Development, 18: 3, 343-359, 1999.

[32] Spauldin, C. L. Motivation in the classroom. New York: McGrawHill, 1992.

[33] Holden, Gary; Barker, Katleen; Meenachan, Thomas and Rosenberg, Gary. Research self efficacy: a new possibility for educational outcomes assessment. Journal of social work education, 35(3), 463, 1999.

[34] Phillips, J. C., \& Russell, R. K. Research self-efficacy, the research training environment, and research productivity among graduate students in counseling psychology. The Counseling Psychologist, 22, 628-641, 1994.

[35] Gall, MD., Borg, WR., \& Gall, JP. Educational research (6th ed.). White Plains, NY: Longman, 1996.

[36] Vallerand, RJ., Blais, MR., Briere, NM., \& Pelletier, LG. Construction et validation de l'Echele de motivation en education (EME). Revue canadienne des sciences du comportement, 21, 323349, 1989.

[37] Deci, E., \& Ryan, R. Handbook of self-determination research. Rochester, NY: University of Rochester Press, 2002.

[38] Deci, EL., \& Ryan, RM. The "what" and "why" of goal pursuits: Human needs and the self-determination of behavior. Psychological Inquiry, 11, 227-268, 2000.

[39] Von Eye, A. \& Schuster, C. Regression analysis for social sciences Models and Applications. San Diego, CA: Academic Press, 1998.

[40] Gomez, E. \& Hill, E. An exploration of self-efficacy as a motivation for rock climbing and its impact on frequency of climbs. Proceedings of the 2007 Northeastern Recreation Research Symposium GTR-NRS-P-23, 2007.

[41] Switzer, KC. Nagy, MS. \& Mullins, ME. The Influence of Training Reputation, Managerial Support, and Self-Efficacy on Pre-Training Motivation and PerceivedTraining Transfer. Applied H.R.M. Research, 10(1), 21-34, 2005.

[42] Shirbaygi, N. \& Salehi, S. Students attitude and self-efficacy in research. 2th conference in Heigher education in Iran, 2010.

[43] Lev, EL., Kolassa, J. \& Bakken, L. Faculty mentors' and students' perceptions of students' research self-efficacy. Nurse Education Today 30, 169-174, 2010. 